\title{
Reliability of anthropometric measurements in children with special needs
}

\author{
Jane Hardy, ${ }_{1}$ Hayley Kuter, ${ }^{2}$ Malcolm Campbell, ${ }^{3}$ Dexter Canoy ${ }^{4}$
}

- Additional material is published online only. To view please visit the journal online (http://dx.doi.org/10.1136/ archdischild-2017-314243)

${ }^{1}$ Department of Community Paediatrics, Manchester

University NHS Foundation Trust, Manchester, UK

${ }^{2}$ Department of Community Paediatric Dietetics, Manchester University NHS Foundation Trust, Manchester, UK

${ }^{3}$ Division of Nursing, Midwifery \& Social Work, School of Health Sciences, The University of Manchester, Manchester, UK

${ }^{4}$ The George Institute for Global Health, University of Oxford, Oxford, UK

\section{Correspondence to} Dr Jane Hardy, Department of Community Paediatrics, Manchester University NHS Foundation Trust, Manchester M40 2JP, UK;

jane.hardy@mft.nhs.uk

Received 6 October 2017 Revised 26 January 2018 Accepted 11 February 2018

Published Online First

17 March 2018
Check for updates

To cite: Hardy J, Kuter $H_{\text {, }}$

Campbell M, et al.

Arch Dis Child

2018:103:757-762.

\section{ABSTRACT}

Objective To determine the reliability of anthropometric and body composition measurements in children with special needs.

Design Observational study.

Setting Specialist support schools (primary and secondary) in Manchester, UK.

Participants 53 children with moderate-to-severe learning disability; 30 non-standers (14 boys) and 23 standers ( 15 boys). Mean ages were 11 years (range 3-20) for non-standers and 12.4 years (range 8-19) for standers.

Measures Anthropometric measures included: height/ length, segmental measures, weight, skinfolds, body circumferences and body composition estimated from bioelectrical impedance analysis (BIA). These were measured twice, 2-4 weeks apart.

Main outcome measures Reliability was assessed using the technical error of measurement (TEM).

Results The TEM for height and supine length was $0.55 \mathrm{~cm}$ for standers and $2.47 \mathrm{~cm}$ for non-standers, respectively. For non-standers, the TEMs for knee height and tibial length were 0.81 and $1.57 \mathrm{~cm}$, respectively. The TEM for weight was $0.55 \mathrm{~kg}$ for standers and $0.75 \mathrm{~kg}$ for non-standers. For skinfold thickness, the TEM was smaller for non-standers than standers. The TEM for mid-upper arm circumference for standers and nonstanders was 0.91 and $0.82 \mathrm{~cm}$, respectively. The TEM for BIA in standers and non-standers was 34.7 and $54.1 \Omega$, respectively. Some measurements, including waist circumferences, were difficult to obtain reliably.

Conclusions Anthropometric and body composition measurements were feasible to obtain in children with special needs. However, the reliability of these measures differs between non-standers and standers and should be considered when choosing appropriate measures.

\section{INTRODUCTION}

Anthropometric measurements of children are important and form part of an overall clinical assessment. Weight, height, skinfold thickness and body circumferences as well as body composition estimates from bioelectrical impedance analysis (BIA) are some of the measures that could be readily obtained in clinics and community settings. Reference values for these measurements are available to allow evaluation of individual nutritional status as well as for public health monitoring. ${ }^{1-6}$ However, these measurements have been shown to have practical and theoretical difficulties in children with cerebral palsy. ${ }^{78}$ Children with special needs, including those with learning difficulties, are a heterogeneous group who may present with poor

\section{What is already known on this topic?}

Anthropometric measures are widely used to assess nutritional status and as indicators of growth and development in children.

- Very little is known about the reliability of anthropometric or body composition measurements in children with special needs.

- Height predicted from segmental measurements has been assessed in children with cerebral palsy; the reliability of this method in children with special needs with a wide range of underlying conditions remains unclear.

\section{What this study adds?}

- Anthropometry and bioelectrical impedance analysis of body composition were feasible to obtain in children with special needs in school settings.

- Reliability of measurements varied largely between children who could stand and those who unable to stand unassisted.

nutritional status, ${ }^{8}$ whereas others may present as being overweight or obese. ${ }^{910}$ We therefore examined the reliability of anthropometric and body composition measurements of children with a variety of special needs who were able or unable to stand unassisted. The practical issues in taking these measurements are also described.

\section{METHODS}

\section{Participants and setting}

A convenience sample of children with moderate-to-severe learning disability was recruited from five specialist support schools in Manchester, UK. We identified children who were able to stand unassisted and usually ambulant ('standers') as well as children who were unable to stand ('non-standers').

\section{Measurements}

Research investigators taking measurements $(\mathrm{JH}$, DB and SC) underwent training, and obtained measurements following a specified protocol. All measurements were taken by the same investigator on two occasions, 2-4 weeks apart. DB measured primary school-aged standers and SC measured secondary school-aged standers. Measurements of non-standers were taken by JH. A school nurse provided assistance, and either DB or SC timed each measurement. 
To reflect usual clinical and community settings, instruments available in each school were used to measure weight and height. Weight was measured to $0.1 \mathrm{~kg}$ on Seca digital scales (Seca, Birmingham, UK) for standers, and Marsden hoist (Marsden Weighing Machine Group, Rotherham, UK) or sitting scales (Weymed Scaleways, Leicester, UK) for non-standers. Standers' heights were measured using a wall-mounted ruler (rulers used included those from Raven Equipment, Essex, UK and from a number of different companies) or a Leicester height metre (Harlow Health Care, Tyne and Wear, UK). Supine length was measured using a Raven Rollameter (Raven Equipment). Non-standers were measured on a gym mat or examination plinth. Upper arm length was measured from the acromion to the head of the radius using Holtain callipers (Holtain, Pembrokeshire, UK). ${ }^{11}$ Tibial length was measured from the tibia to the sphyrion using a steel tape measure. ${ }^{11}$ Knee height was measured with the knee and ankle at 90 degrees from the heel to the anterior surface of the thigh over the femoral condyle using Holtain callipers. ${ }^{11}$ All height or length measurements were taken to $0.1 \mathrm{~cm}$. All segmental measurements were taken on the child's right side. Supine length was estimated using Stevenson's equations ${ }^{11}$ for all three segmental measurements. When feasible, body mass index (BMI) was calculated from weight/height2.

Skinfold thickness was measured to $0.1 \mathrm{~mm}$ using Holtain callipers. ${ }^{512}$ Two measurements were taken, and a third measurement was additionally taken if the difference between the first two measurements was $>0.2 \mathrm{~mm}$. Mid-upper arm circumference (MUAC) was measured to $0.1 \mathrm{~cm}$ using a Lasso-O Child Growth Foundation tape as described by Frisancho. ${ }^{6}$ True waist circumference was measured midway between the tenth rib and the iliac crest to $0.1 \mathrm{~cm}$ using a vinyl-coated polyester tape measure. ${ }^{2}$ Umbilical waist circumference was measured at the level of the umbilicus to $0.1 \mathrm{~cm}$.

BIA was performed with the child supine using Bodystat 1500 (Bodystat, Isle of Man, UK). Wrist electrodes were applied between the bony prominences of the radial and ulna heads and foot electrodes between the bony prominences of the tibia and fibula at the ankle. Measurement of the raw impedance values was taken after the child had relaxed for 4-5 min. Fat-free mass was calculated from the raw impedance values using the equations by Houtkooper et al. ${ }^{1}$ Fat mass was calculated by subtracting fat-free mass from body weight. Fat-free mass and fat-mass indices were calculated as: fat-free mass/height ${ }^{2}$ and fat mass/height ${ }^{2}$, respectively. ${ }^{13}$ The hand-foot measurement using Bodystat 1500 was chosen, as this has performed better in validity studies than leg-leg impedance measurement. ${ }^{14}$

Reasons for not achieving a measurement or any specific difficulty in taking measurements were also recorded.

\section{Statistical analysis}

Data from 53 children formed the basis of our analysis. We analysed the characteristics of the children based on their ability to stand unassisted. We also analysed the feasibility and other practical issues of taking measurements in standers and non-standers, and noted some of the challenges and difficulties encountered. To assess reliability of repeated measures collected over time, we used paired t-test to compare the difference in measurements taken between the two different time points; to express the error margin we calculated the technical error of measurement (TEM). Measured and estimated supine length from supine measurements were compared using the Bland-Altman limits of agreement (LOA). ${ }^{15}$ We also report the $\mathrm{P}$ values and 95\% CIs, along with the coefficient of variability where appropriate. We reported SD scores (SDS) for skinfold thickness. The triceps and subscapular SDS scores were used as a convenient method for expressing 'fatness' in both groups as they can be used serially for comparison. ${ }^{16}$ We analysed our data using StatsDirect V.2.7.2 (StatsDirect, Cheshire, UK).

\section{RESULTS}

\section{Subject characteristics}

Twenty-three children (15 boys) were able to stand, whereas 30 children (14 boys) were unable to stand. The mean (range) age of non-standers was 10.8 years $(3-19.7)$ and standers was 12.4 years $(8.3-19.3)$.

Diagnoses of the 30 non-standers included: cerebral palsy $(n=13)$, undiagnosed severe neurological conditions $(n=5)$, spina bifida $(n=2)$, neuronal migration disorder $(n=1)$, partial deletion of chromosome $13(n=1)$, severe learning difficulties associated with severe epilepsy $(n=1)$ and non-ketotic hyperglycinaemia $(n=1)$. Six non-standers had no information available regarding their diagnoses. Of the non-standers, 12 had a gastrostomy and 10 had a scoliosis.

Diagnoses of 23 children who were able to stand included: Down syndrome $(n=4)$, severe learning disability of unknown cause $(n=9)$, SCN1 mutation with severe epilepsy $(n=1)$, Klinefelter's syndrome $(n=1)$, Cri-du-chat $(n=1), 16 \mathrm{p} 11.2$ microdeletion $(n=1)$ and exposure to alcohol and anticonvulsants in utero $(n=1)$. There was no information regarding the diagnoses of the remaining five children.

\section{Feasibility of obtaining measurements}

Measurement of weight and height was possible in all standers. Weight was obtained in 29 of 30 non-standers and supine length was possible in 28 of 30 non-standers. Among the 30 non-standers, segmental lengths including upper arm length, tibial length and knee height were obtained in 27, 30 and 28 children, respectively. True waist circumference was obtained in 28 of 30 non-standers and 19 of 23 standers, and umbilical waist circumference in 26 non-standers and 17 standers.

Skinfold thickness measurement was feasible among non-standers, whereas standers tended to have poorer co-operation and did not like the callipers. Supra-iliac skinfold was not feasible in the non-standers, and was measurable in less than half of the standers (10 of 23). Triceps skinfold was achievable in 27 of 30 non-standers and 18 of 23 standers. Subscapular skinfold was achievable in 27 of 30 non-standers and 14 of 23 standers.

The time taken to obtain measurements in standers and non-standers is shown in online supplementary table S1. Measuring supine length in non-standers took twice as long as measuring height in standers. In contrast, it took longer to obtain subscapular skinfold thickness measurement in standers than in non-standers. It also took longer to measure weight in non-standers as they needed to be hoisted or transferred to sitting scales. The proportion of first 'successful' measurements are reported in online supplementary table S2.

Challenges encountered in taking measurements included: dystonic posturing, fixed flexion deformities, presence of an ileal conduit, difficulty locating landmarks in the obese or those with scoliosis and distress or failure to cooperate (see online supplementary table S3 to S6).

\section{Reliability of measurements performed}

Table 1 shows the reliability of taking anthropometric measurements. Compared with standers, the TEM for non-standers was larger for height/length, weight and BMI but not for waist 
Table 1 Technical error of measurement between two repeat measurements for anthropometric measures for body sizes in children with special needs taken 2-4 weeks apart

\begin{tabular}{llllll}
\hline & $\begin{array}{l}\text { Number of paired } \\
\text { measurements }(\mathrm{n})\end{array}$ & $\begin{array}{l}\text { Mean of paired } \\
\text { measurements }\end{array}$ & $\begin{array}{l}\text { Difference between } \\
\text { first and second measurement } \\
\text { Mean }(95 \% \mathrm{Cl})\end{array}$ & $\begin{array}{l}\text { Technical error of } \\
\text { P values }\end{array}$ \\
\hline measurement (CV)
\end{tabular}

Body mass index: for standers=weight/height ${ }^{2}$, for non-standers=weight/supine length ${ }^{2} ; \mathrm{CV}: 100 \mathrm{xTEM} /$ mean of measurements taken, expressed as a percentage. Difference in means $P$ value assessed by paired t test. TEM $=\sqrt{\sum} d^{2} / 2 n$, where $d$ is difference between two measurements and $n$ is number of measurements.

${ }^{*}$ True waist circumference - measured midway between the 10th rib and the iliac crest.

CV, coefficient of variability.

circumference. The reliability of taking segmental measurements for non-standers is shown in table 2.

The TEM for knee height was smaller than for tibial length or upper-arm length. The TEM for measured supine length in all non-standers was large. However, the TEM for both segmental and supine length in those aged $<12$ years was smaller. Excluding the participants with scoliosis from the analysis gave a TEM of 2.7, which was similar to the whole group (2.47).

Table 3 shows the LOA between measured supine length and that estimated from segmental measurements. Estimated supine lengths from segmental measurements compared with measured supine length showed wide LOA. Although the TEM for knee height was low compared with tibial length, the estimated supine lengths showed a wider LOA than for tibial length. The LOA for estimated length from upper-arm length were wide.

Table 4 shows the TEM for MUAC and skinfold measurements, which are presented in absolute measures as well as standardised values. Non-standers had lower TEM for skinfold measures than standers, whereas the TEM for MUAC was similar for both standers and non-standers. Taking BIA measurements was possible in 25 of $30(83 \%)$ non-standers but only 17 of 23 (74\%) standers (see online supplementary table S2). Adiposity indices derived from BIA are shown in table 5. The raw impedance values show larger TEM for non-standers than for standers.

\section{DISCUSSION}

In this study, we describe the reliability of obtaining anthropometric and BIA measurements in children with special needs. Our results show that the feasibility of taking measurements and the variability in repeated measurements depended on the specific condition of the child, particularly whether or not the child is able to stand unassisted.

\section{Height, weight and body mass index}

For both groups of children, particularly the non-standers, the reliability of weight measurements, taken 2-4 weeks apart, was somewhat poor. Possible reasons for this large variability may have been due to differences in the children's condition at that time, for example, timing of enteral feeds or meals, constipation or fluid retention.

Poor co-operation or inability to lie still, particularly in those with dystonic movements, were some of the challenges involved in obtaining length measurement, as it involved placing a rollameter underneath the child and 'stretching' the legs. The presence of scoliosis did not appear to affect the repeatability of the measurement. However, the reliability of supine length was better in those aged under 12 years than the remaining older children. It is possible that knee and hip contractures may have

Table 2 Technical error of measurement between two repeat measurements of segmental length for non-standers taken 2-4 weeks apart

\begin{tabular}{|c|c|c|c|c|c|}
\hline & $\begin{array}{l}\text { Number of paired } \\
\text { measurements (n) }\end{array}$ & $\begin{array}{l}\text { Mean of paired } \\
\text { measurements }\end{array}$ & $\begin{array}{l}\text { Difference between } \\
\text { first and second measurement } \\
\text { Mean }(95 \% \mathrm{Cl})\end{array}$ & $P$ values & $\begin{array}{l}\text { Technical error of } \\
\text { measurement (CV) }\end{array}$ \\
\hline Upper arm length $(\mathrm{cm})$ & 25 & 27.2 & $0.5(-1.3$ to 0.3$)$ & 0.2 & $1.37(5.03)$ \\
\hline Tibial length (cm) & 27 & 29.4 & $0.2(-0.7$ to 1.1$)$ & 0.6 & $1.57(5.35)$ \\
\hline Tibial length $(\mathrm{cm})<12$ years & 17 & 26.8 & $-0.23(-0.97$ to 0.51$)$ & 0.26 & $1.00(3.74)$ \\
\hline Knee height $(\mathrm{cm})$ & 27 & 37.3 & $0.1(-0.6$ to 0.4$)$ & 0.7 & $0.81(2.18)$ \\
\hline Knee height $(\mathrm{cm})<12$ years & 17 & 33.6 & $-0.23(-0.90$ to 0.45$)$ & 0.24 & $0.91(2.72)$ \\
\hline Supine length $(\mathrm{cm})$ & 25 & 126.0 & $0.3(-1.1$ to 1.8$)$ & 0.6 & $2.47(1.96)$ \\
\hline Supine length $(\mathrm{cm})<12$ years & 15 & 116.4 & $-0.058(-1.19$ to 1.08$)$ & 0.46 & $1.39(1.20)$ \\
\hline
\end{tabular}

$T E M=\sqrt{ } d^{2} / 2 n$, where $d$ is the difference between two measurements and $n$ isthe number of measurements. CV: $100 x T E M / m e a n$ of measurements taken, expressed as a percentage. 
Table 3 Limits of agreement between mean measured supine length (1 and 2) and mean estimated supine length from segmental measures (1 and 2), with measures 1 and 2 taken 2-4 weeks apart

\begin{tabular}{|c|c|c|c|c|c|c|}
\hline & $\begin{array}{l}\text { Number of paired } \\
\text { measure ments }(n)\end{array}$ & $\begin{array}{l}\text { Mean of measured } \\
\text { supine length } 1 \\
\text { and } 2 \text { (SD) }\end{array}$ & $\begin{array}{l}\text { Mean of estimated } \\
\text { length } 1 \text { and } 2 \text { (SD) }\end{array}$ & $\begin{array}{l}\text { Difference between } \\
\text { measured and estimated } \\
\text { Mean }(95 \% \mathrm{Cl})\end{array}$ & $P$ values & $\begin{array}{l}95 \% \text { Limits of } \\
\text { agreement }\end{array}$ \\
\hline Estimated* length from upper arm length & 22 & $124.7(19.7)$ & $140.2(24.5)$ & $-15.5(-20.2$ to -10.7$)$ & $<0.001$ & -36.5 to 5.5 \\
\hline Estimated* length from tibial length & 25 & $126.0(19.4)$ & $126.3(19.9)$ & $-0.26(-2.15$ to 1.64$)$ & 0.8 & -9.2 to 8.7 \\
\hline Estimated ${ }^{*}$ length from knee height & 25 & $126.0(19.4)$ & $124.8(19.8)$ & $1.3(-1.1$ to 3.7$)$ & 0.3 & -10.0 to 12.5 \\
\hline Estimated* length from $T L<12$ years & 15 & $116.1(17.1)$ & $116.3(18.09)$ & $-0.13(-2.7$ to 2.4$)$ & 0.5 & -9.2 to 8.9 \\
\hline Estimated* length from $\mathrm{KH}<12$ years & 15 & $116.1(17.1)$ & $113.95(17.22)$ & $2.19(0.02$ to 4.36$)$ & 0.02 & -5.5 to 9.9 \\
\hline
\end{tabular}

$\mathrm{KH}$, knee height; TL, tibial length.

${ }^{*}$ Based on Stevenson's method ${ }^{11}$ using the following equations to estimate supine length: $(4.35 \mathrm{x}$ upper arm length $)+21.8,(3.26 \mathrm{x}$ tibial length $)+30.8$, (2.69 $\mathrm{x}$ knee height) + 24.2.; difference in means and significance ( $P$ value) assessed by paired t-test.

reduced the reliability of supine length in the older children. Height measurement for those who can stand was achieved in all children with relatively good repeatability.

Measurements of height and weight were more difficult to assess and less reliable in non-standers than in standers. Poor repeatability of weight and supine length measurements in non-standers affected the reliability of their BMI.

\section{Segmental height for non-standers}

Segmental measurements as a means of estimating supine length showed poor repeatability using Stevenson's equations. ${ }^{11}$ Estimation of length from segmental measurements depends on both the reliability of the measurement procedure and the prediction equation chosen. ${ }^{17}$ Haapala et al investigated the agreement between total recumbent length of children with cerebral palsy and that estimated from a number of different equations and they found only poor to moderate agreement. ${ }^{17}$

The TEM for knee height in our study was larger than that reported by Stevenson, ${ }^{11}$ but that study only included children with the same condition (cerebral palsy) with a median age of 4.8 years. We found that the LOA between the measured supine length and that estimated from knee height for those aged $<12$ years were much smaller, suggesting that this equation may be appropriate in this age group. Although the TEM for knee height in our study was considerably smaller than that for tibial length, this did not translate into better prediction of supine length, as the estimated supine length from tibial length showed narrower LOA. It is possible that the TEM was smaller for knee height because it involves using callipers resting on bony prominences, whereas tibial length involves locating a landmark and applying a tape measure.

Knee height has been measured in a group of children with moderate-to-severe cerebral palsy (Gross Motor Function Classification System levels III-V) and has been used to produce growth curves that relate to severity of condition and healthcare use. ${ }^{18}$ The population measured in our study was heterogeneous. Our results suggest that simply using serial measurements of knee height may be useful to assess individual trends in growth for those unable to stand.

\section{Body circumferences and skinfold thickness}

Waist circumference measurements (both true and umbilical) were difficult to achieve and showed poor reliability in both groups. This was mainly due to problems in locating landmarks

Table 4 Technical error of measurement between two repeat measurements of adiposity using skinfold thickness taken 2-4 weeks apart

\begin{tabular}{|c|c|c|c|c|c|}
\hline & $\begin{array}{l}\text { Number of paired } \\
\text { measurements }(n)\end{array}$ & $\begin{array}{l}\text { Mean of paired } \\
\text { measurements }\end{array}$ & $\begin{array}{l}\text { Difference between } \\
\text { first and second measurement } \\
\text { Mean }(95 \% \mathrm{Cl})\end{array}$ & $P$ values & $\begin{array}{l}\text { Technical error } \\
\text { measurement (CV) }\end{array}$ \\
\hline \multicolumn{6}{|l|}{ Non-standers $(n=30)$} \\
\hline Mid-upper arm circumference $(\mathrm{cm})$ & 28 & 22.1 & $-0.5(-0.9$ to 0.1$)$ & 0.03 & $0.82(3.72)$ \\
\hline Triceps skinfold thickness (mm) & 27 & 15.5 & $-0.5(-1.6$ to 0.6$)$ & 0.4 & $1.94(12.5)$ \\
\hline Triceps SDS & 27 & 0.75 & $-0.13(-0.36$ to 0.11$)$ & - & $0.45(59.43)$ \\
\hline Biceps skinfold thickness (mm) & 26 & 9.3 & $-0.0(-1.5$ to 1.5$)$ & 1.0 & $2.36(25.6)$ \\
\hline Subscapular skinfold thickness (mm) & 26 & 12.1 & $-0.5(-2.0$ to 0.3$)$ & 0.2 & $1.28(8.3)$ \\
\hline Subscapular SDS & 26 & 0.33 & 1.23 (0.48 to 1.97$)$ & - & $0.34(102.33)$ \\
\hline Suprailiac skinfold thickness (mm) & - & - & - & - & - \\
\hline \multicolumn{6}{|l|}{ Standers $(n=23)$} \\
\hline Mid-upper arm circumference (cm) & 22 & 26.1 & $-0.1(-0.7$ to 0.5$)$ & 0.7 & $0.91(3.5)$ \\
\hline Triceps skinfold thickness (mm) & 17 & 17.2 & $1.4(-0.7$ to 3.5$)$ & 0.2 & $2.99(17.4)$ \\
\hline Triceps SDS & 17 & 1.09 & $-0.17(-0.45$ to 0.12$)$ & 0.11 & $0.39(36.3)$ \\
\hline Biceps skinfold thickness (mm) & 16 & 16.4 & $1.1(-1.2$ to 3.5$)$ & 0.3 & $3.11(19.03)$ \\
\hline Subscapular skinfold thickness (mm) & 12 & 16.4 & $-2.6(5.4$ to 0.2$)$ & 0.06 & $3.49(21.29)$ \\
\hline Subscapular SDS & 12 & 1.18 & $-0.12(-0.3$ to 0.06$)$ & 0.08 & $0.2(17.5)$ \\
\hline Suprailiac skinfold thickness $(\mathrm{mm})$ & 8 & 18.9 & $0.1(-3.1$ to 4.0$)$ & 0.8 & $2.79(14.8)$ \\
\hline
\end{tabular}

SDS using LMS method ${ }^{12}$; difference in means $P$ value assessed by paired $t$-test; TEM $=\sqrt{ } \sum d^{2} / 2 n$, where $d$ is difference between two measurements and $n$ is no. of measurements. $\mathrm{CV}$ : 100xTEM/mean of measurements taken, expressed as a percentage.

CV, coefficient of variability; LMS, L skewness M median S coefficient of variation; SDS, SD score 
Table 5 Technical error of measurement between two repeat measurements of body composition using bioimpedance analysis taken 2-4 weeks apart

\begin{tabular}{|c|c|c|c|c|c|}
\hline & $\begin{array}{l}\text { Number of paired } \\
\text { measurements (n) }\end{array}$ & $\begin{array}{l}\text { Mean of paired } \\
\text { measurements }\end{array}$ & $\begin{array}{l}\text { Difference between } \\
\text { first and second measurement Mean } \\
(95 \% \mathrm{Cl})\end{array}$ & $P$ values & $\begin{array}{l}\text { Technical error of } \\
\text { measurement (CV) }\end{array}$ \\
\hline \multicolumn{6}{|l|}{ Non-standers $(n=30)$} \\
\hline Impedance $(\Omega)$ & 22 & 878.9 & $0.05(-34.7$ to 34.8$)$ & 0.99 & $54.1(6.16)$ \\
\hline Fat-free mass index $\left(\mathrm{kg} / \mathrm{m}^{2}\right)^{*}$ & 21 & 12.9 & & & $0.67(5.25)$ \\
\hline Fat mass index $\left(\mathrm{kg} / \mathrm{m}^{2}\right) \dagger$ & 21 & 6.46 & & & $0.8(12.39)$ \\
\hline \multicolumn{6}{|l|}{ Standers $(n=23)$} \\
\hline Impedance $(\Omega)$ & 16 & 635.6 & $2.6(-24.4$ to 29.5$)$ & 0.8 & $34.7(5.45)$ \\
\hline Fat-free mass index $\left(\mathrm{kg} / \mathrm{m}^{2}\right)^{*}$ & 16 & 16.41 & & & $0.53(3.23)$ \\
\hline Fat mass index $\left(\mathrm{kg} / \mathrm{m}^{2}\right) \dagger$ & 16 & 6.65 & & & $0.59(8.93)$ \\
\hline
\end{tabular}

Difference in means $P$ value assessed by paired t-test. TEM $=\sqrt{\sum} \mathrm{d}^{2} / 2 \mathrm{n}$, where $\mathrm{d}$ is difference between two measurements and $\mathrm{n}$ is no. of measurements. CV: \%TEM $=100 \mathrm{xTEM} /$ mean.

${ }^{*}$ Calculated using the equations by Houtkooper et $\mathrm{al}^{1}: \mathrm{FFM}=0.61 \times \mathrm{ht}^{2} /$ impedance $+(0.25 \mathrm{xweight})+1.31$. Fat-free mass index=fatfree mass/supine length ${ }^{2}{ }^{13}$

tFat mass=body weight-fat-free mass. Fat mass index=fat mass/supine length ${ }^{2}{ }^{13}$

CV, coefficient of variability.

in those who were overweight, in wheelchairs, wearing a spinal brace or with ileal conduits.

MUAC has been used in combination with skinfold thickness to estimate cross-sectional fat and lean mass in the upper arm. ${ }^{6}$ However, it correlates highly with skinfold thickness so the use of either measure may suffice. ${ }^{19}$ In our study, MUAC seemed to provide moderate reliability.

The TEM for triceps and subscapular skinfolds were smaller for the non-standers than the standers and this is likely to reflect the difficulty in taking skinfold measurements among standers.

\section{Bioelectrical impedance analysis}

The raw impedance values for non-standers showed a large error of measurement. This may be due to differences within the subject at different time periods, particularly hydration. For non-standers, the reliability of either weight or supine length could affect the reliability of the estimated body composition. For standers, the TEM for the raw impedance was smaller. However, obtaining body composition measures using BIA was easier to achieve than skinfolds, and may provide an alternative means of estimating body composition in this group of children.

\section{Strengths and limitations}

We studied the feasibility and reliability of measuring a heterogeneous group of children with special needs. There are very few studies reporting anthropometric measurements in these children. We replicated usual clinical or healthcare settings in the community by using locally available equipment in the school setting. Children were grouped according to their ability to stand which offers a practical approach. A strength of our study is that it describes measures likely to be feasible and identifies what challenges may need to be addressed to achieve these measurements.

For the standers, all the measurements were taken on two occasions by the same individual, but the primary school-aged standers were measured by one individual and the secondary school-aged standers by a different individual. This approach may have introduced an element of bias as interobserver TEMs could not be calculated.

\section{CONCLUSION}

Our study shows that a number of simple anthropometric measurements could be used to assess growth and body composition in children with special needs. However, the feasibility and reliability of obtaining these measures vary with the type of measurement and the ability to stand. Understanding the sources of variation in any choice of measurement for use in clinical or community settings may help reduce errors and improve reliability of these measurements. Future research may focus on how these measurements relate to growth and development and on the metabolic health in children with special needs.

Acknowledgements The authors would like to thank all the participants, their parents and carers for their willingness to be included in the study; Diane Boyd (DB) and Stephanie Campbell (SC) from the University of Ulster (Department of Nutrition) who undertook measurements of the standing children and were involved in data collection; Andy Vail (R\&D Support Unit Clinical Sciences Building Salford Royal NHS Foundation Trust) for statistical review and advice; Lisa Kauffmann (Department of Community Paediatrics, CMFT) and Helen McCarthy (University of Ulster) for helpful discussions and support.

Collaborators Boyd, Diane. Campbell, Stephanie

Contributors $\mathrm{JH}$ : lead investigator, developed study design, research protocol, ethics application, data collection, analysis and manuscript. SC: involved in data collection in secondary schools. DB: involved in data collection in the primary specialist support schools. MC: provided statistical review and intellectual input. HK: provided important intellectual input and contributed in the revision of subsequent versions of the manuscript. DC: provided intellectual input and contributed in the revision of the manuscript.

Funding This research received no specific grant from any funding agency in the public, commercial or not-for-profit sectors.

Competing interests None declared.

Patient consent Parental/guardian consent obtained.

Ethics approval Ethical approval was obtained from the National Research Ethics Service Committee North West—Greater Manchester South (07/Q1403/68).

Provenance and peer review Not commissioned; externally peer reviewed.

(c) Article author(s) (or their employer(s) unless otherwise stated in the text of the article) 2018. All rights reserved. No commercial use is permitted unless otherwise expressly granted.

\section{REFERENCES}

1 Houtkooper LB, Lohman TG, Going SB, et al. Validity of bioelectric impedance for body composition assessment in children. J App/ Physiol 1989;66:814-21.

2 McCarthy HD, Jarrett KV, Crawley HF. The development of waist circumference percentiles in British children aged 5.0-16.9 y. Eur J Clin Nutr 2001;55:902-7.

3 Norris B, Wilson JR. Child-data: the handbook of child measurements and capabilities - data for design safety. UK: Department of Trade and Industry, 1995.

4 Cole TJ, Freeman JV, Preece MA. Body mass index reference curves for the UK, 1990. Arch Dis Child 1995;73:25.9. 


\section{Original article}

5 Tanner JM, Whitehouse RH. Revised standards for triceps and subscapular skinfolds in British children. Arch Dis Child 1975;50:142-5.

6 Frisancho AR. New norms of upper limb fat and muscle areas for assessment of nutritional status. Am J Clin Nutr 1981;34:2540-5.

7 Stallings VA, Charney EB, Davies JC, et al. Nutrition-related growth failure of children with quadriplegic cerebral palsy. Dev Med Child Neurol 1993;35:126-38.

8 Samson-Fang LJ, Stevenson RD. Identification of malnutrition in children with cerebral palsy: poor performance of weight-for-height centiles. Dev Med Child Neurol 2000;42:162-8.

9 Bandini LG, Curtin C, Hamad C, et al. Prevalence of overweight in children with developmental disorders in the continuous national health and nutrition examination survey (NHANES) 1999-2002. J Pediatr 2005;146:738-43.

10 Marshall D, McConkey R, Moore G. Obesity in people with intellectual disabilities: the impact of nurse-led health screenings and health promotion activities. J Adv Nurs 2003;41:147-53.

11 Stevenson RD. Use of segmental measures to estimate stature in children with cerebral palsy. Arch Pediatr Adolesc Med 1995;149:658-62.
12 Davies PS, Day JM, Cole TJ. Converting Tanner-Whitehouse reference tricep and subscapular skinfold measurements to standard deviation scores. Eur J Clin Nutr 1993;47:559-66.

13 Wells JC. A critique of the expression of paediatric body composition data. Arch Dis Child 2001;85:67-72.

14 Reilly JJ, Wilson J, Durnin JV. Determination of body composition from skinfold thickness: a validation study. Arch Dis Child 1995;73:305-10.

15 Bland JM, Altman DG. Statistical methods for assessing agreement between two methods of clinical measurement. Lancet 1986;1:307-10.

16 Wells JC, Fewtrell MS. Measuring body composition. Arch Dis Child 2006;91:612-7.

17 Haapala H, Peterson MD, Daunter A, et al. Agreement between actual height and estimated height using segmental limb lengths for individuals with cerebral palsy. Am J Phys Med Rehabil 2015;94:539-46.

18 Stevenson RD, Conaway M, Chumlea WC, et al. Growth and health in children with moderate-to-severe cerebral palsy. Pediatrics 2006;118:1010-8.

19 Chomtho S, Fewtrell MS, Jaffe A, et al. Evaluation of arm anthropometry for assessing pediatric body composition: evidence from healthy and sick children. Pediatr Res 2006;59:860-5. 